\title{
A Case of Withdrawal Psychosis from Internet Addiction Disorder
}

\author{
Ahyoung Paik, Daeyoung Oh*, and Daeho Kim ${ }^{\bowtie}$ \\ Department of Psychiatry, Hanyang University Guri Hospital, Guri, Republic of Korea
}

Similar to substance use disorder, patients with Internet addiction disorder (IAD) show excessive use, tolerance and withdrawal symptoms. We report a case of a patient with withdrawal psychosis who showed persecutory delusion and disorganized behaviors in addition to common withdrawal symptoms such as agitation and irritability. A 25-year-old male developed a full-blown psychotic episode within one day after discontinuing an Internet game that he had been playing for at least eight hours a day for two years. Upon admission, he had no abnormal brain imaging findings and laboratory tests. With antipsychotic medication (quetiapine up to $800 \mathrm{mg}$ ), his psychotic symptoms rapidly subsided and after four days of treatment, he no longer showed any signs of psychosis. This case report suggests that brief psychosis can develop during withdrawal from long-term excessive use of an Internet and the central pathology beneath the IAD is more likely a form of addiction than impulse control.

Psychiatry Investig 2014;11(2):207-209

Key Words Internet addiction, Psychotic symptoms, Withdrawal, Behavior addiction.

\section{INTRODUCTION}

Internet addiction disorder (IAD) is more significant than other behavior addictions regarding its high prevalence even in children and its negative impact on mental health. Christakis reports that $2-18 \%$ of Asian children are addicted to the Internet ${ }^{1}$ and numerous reports demonstrate its association with severe psychopathology and poor psychosocial functioning. ${ }^{2,3}$ Additionally, it has been demonstrated that long-term addiction can induce decreased gray matter volume in certain areas of the brain. ${ }^{4}$

Currently, no formal psychiatric nomenclature exists for IAD; however, along with pathological gambling, there is a movement to list Internet addiction within the category of behavior addiction in the DSM-5. ${ }^{5}$ As with other addiction problems, patients with IAD show excessive use, tolerance and withdrawal symptoms. A study on the diagnostic criteria of IAD revealed that $95.5 \%$ of the patients reported withdrawal

Received: April 13, 2013 Revised: May 23, 2013

Accepted: May 28, 2013 Available online: April 11, 2014

$\triangle$ Correspondence: Daeho Kim, MD, PhD

Department of Psychiatry, Hanyang University Guri Hospital, 153 Gyeongchunro, Guri 471-701, Republic of Korea

Tel: +82-31-560-2274, Fax: +82-31-554-2599

E-mail: dkim9289@hanyang.ac.kr

*Current Affilation: Department of Psychiatry, CHA Bundang Medical Center, CHA University School of Medicine, Seongnam, Republic of Korea

(a) This is an Open Access article distributed under the terms of the Creative Commons Attribution Non-Commercial License (http://creativecommons.org/licenses/bync/3.0) which permits unrestricted non-commercial use, distribution, and reproduction in any medium, provided the original work is properly cited. symptoms, placing these as the second most common symptoms after preoccupation (96.4\%). ${ }^{6}$ Thus, symptoms of withdrawal are crucial and have heuristic value in the recognition and management of IAD. Recently, one case report has described the emergence of psychotic symptoms during withdrawal from Internet addiction. ${ }^{7}$ Here, we report another case of an adult patient with IAD who developed a psychotic episode after abrupt discontinuation of long-term excessive Internet use.

\section{CASE}

A 25-year-old male presented at our emergency department complaining of agitation, aggressiveness, delusion, and disorganized behavior that developed within a day after discontinuation of Internet use. Five days prior to his emergency room admission, he abruptly quit an online game that he had played daily for 8 to 12 hours for two years, partially of his own will and partially due to his parents' persuasion. However, he immediately became anxious and agitated; he could not concentrate or sleep. The next day, he still felt agitated and sometimes lethargic, and he reported watching a TV program that told him that electromagnetic waves could cause sexual dysfunction. This caused him to become excessively anxious and preoccupied with the idea that he had problems with erection. He reported removing all electronic cords to his computer and other electronic equipment and wandered around worrying about sexual dysfunction. He asked his sister to have sexual intercourse with 
him and demanded that his father follow any orders he made. On the day of admission, the patient waited behind the door of his house to ambush his father and he attacked his father with a knife, leading to an actual injury.

At the intake interview, he demonstrated continued persecutory delusions (i.e., the electromagnetic waves made him impotent), impaired reality testing, and psychomotor agitation. When describing his sexual problems to a doctor, he removed all of his own clothes.

Laboratory tests, including drug screening and a brain computed tomography (CT) scan, revealed no abnormalities. He denied any personal of family history of mental illness. Although he showed a decline in psychosocial functions, such as difficulty maintaining a stable job and disturbed a sleep-awake cycle due to excessive gaming, there were no suspected previous psychiatric morbidities except IAD.

We began a rapid titration of quetiapine up to $800 \mathrm{mg}$ to control his impulsivity and psychotic symptoms. We observed rapid improvement of symptoms within four days of treatment initiation. At first he claimed that he was not able to remember what had happened, but he gradually began to remember and explained his behaviors. He said that he became extremely anxious and restless within a short period of time. Without noticing, he was overwhelmed with the idea that he was sexually deficient for no specific reasons. He also acknowledged hearing voices of women and men after withdrawal from using the Internet, but could not remember the content. On the fifth day of admission, he had no psychotic symptoms and reality testing was intact. He became logical and relevant. A full psychological assessment was performed on the seventh day of admission that indicated no evidence of psychotic or mood symptoms. After two weeks of inpatient treatment, he was discharged.

Since high school, the patient played online games for approximately five hours a day, either at home or at a PC bang (Internet café). However, two years ago, as he became more skilled at a massive multiplayer online role-playing game (MMORPG), called Lineage 2 , he was able to collect many game items that could be exchanged for money. Hence, he spent an increasing amount of time more than 8-10 hours a day. During that time, he sometimes spent a day without eating, talking or sleeping. Of his own volition, he attempted to cut down his time spent gaming, but always failed. He said that the game gave him a sense of satisfaction and self-esteem, and it made him feel as though he was "being a god." He described playing the game as better than talking and meeting people in the real world.

He fulfilled the diagnostic criteria for IAD as described by Goldberg: tolerance for excessive time on the Internet; withdrawal symptoms (psychomotor agitation, anxiety, and irritability); craving and failure to decrease or discontinue the use; continued use despite negative life consequences; and social and occupational impairment.

Six months after discharge from the hospital, he is currently employed with a part-time job and has remained on a small dose of medication (quetiapine $12.5 \mathrm{mg}$ ) for sleep. He has not played the online game since admission and has not shown any signs of psychosis.

\section{DISCUSSION}

To the best of our knowledge, this is the second report of psychosis during Internet withdrawal and the first case in an adult. The other reported case is one of 15-year old Indian boy who developed persecutory and bizarre delusions after 36 hours of being disconnected from the Internet. ${ }^{6}$ This case is very similar to ours in terms of the course and manifestation of symptoms. First, both cases had at least two prior years of excessive Internet use (at several hours per day) and functional impairment. The emergence of psychotic symptoms occurred within a day and half after abstinence. Both cases showed rapid symptom improvement and full recovery from psychotic episodes within one or two weeks. The themes of persecutory delusion were related to computer and technology; our patient had delusions about electromagnetic waves from the PC and the adolescent patient experienced delusions about password hijacking and a chip inserted into the PC.

Similar to substance use disorder, most patients with IAD show withdrawal symptoms; however, most typically report mood or anxiety symptoms such as dysphoria, anxiety, irritability and boredom. ${ }^{6}$ Individuals with a chemical addiction often show psychotic symptoms; nearly half of those who abuse cocaine (47.7\%) or cannabis (44.8\%) report experiencing psychotic symptoms during the use or withdrawal of those specific substances. ${ }^{8}$ Our case suggests that a behavior addiction such as IAD may cause withdrawal psychosis in some vulnerable individuals. One study noted that $22 \%$ (4/18) of pathological gamblers without comorbid alcohol dependence reported that they often or always experience hallucinations as withdrawal symptoms. ${ }^{9}$

The vulnerability for this emergence of psychotic symptoms is unclear. A recent study noted that cannabis use in adolescence predicts future psychotic vulnerability and vice versa, suggesting that addiction may foster the psychosis but psychosis-prone individuals may abuse substances as well. ${ }^{10}$

Differential diagnosis of this case included organic psychosis and bipolar 1 disorder, single episode manic severe with psychotic features. Collateral information from family members and psychological and laboratory tests did not support the possibility of a psychotic disorder associated with substance abuse or a general medical condition. Furthermore, he did not meet criteria for a mood episode, although he demonstrated irrita- 
bility throughout the course of the illness.

It is not certain that his psychotic symptoms reflected the contents of the game or Internet use. However, auditory hallucinations from men and women may reflect actual voices of the game characters. Additionally, attacking his father with a knife is similar to one of the main themes of the game (i.e., kill the enemy with various weapons).

Given the emergence of withdrawal psychosis in this case, $\mathrm{IAD}$ may be better categorized as an addiction rather than impulse control disorder. It was noted that Internet addiction may lead to abnormal changes in white matter structure that are similar to those observed in chemical dependency. ${ }^{11}$ Further studies are necessary to investigate the nature and course of withdrawal symptoms associated with IAD and to compare with those of substance use disorders and other forms of behavior addiction.

\section{REFERENCES}

1. Christakis DA. Internet addiction: a 21st century epidemic? BMC Med 2010;8:61.
2. Flisher C. Getting plugged in: an overview of internet addiction. J Paediatr Child Health 2010;46:557-559.

3. Murali V, George S. Lost online: an overview of Internet addiction. Adv Psychiatr Treat 2007;13:24-30.

4. Yuan K, Qin W, Wang G, Zeng F, Zhao L, Yang X, et al. Microstructure abnormalities in adolescents with Internet addiction disorder. PLoS One 2011;6:e20708.

5. Holden C. Psychiatry. Behavioral addictions debut in propsed DMS-V. Science 2010;327:935

6. Tao R, Huang X, Wang J, Zhang H, Zhang Y, Li M. Proposed diagnostic criteria for Internet addiction. Addiction 2010;105:556-564.

7. Golberg I. Internet Addiction Disorder (IAD) - Diagnostic Criteria (1996). No longer available at www.cog.brown.edu/brochure/people/duchon/ humor/Internet.addiction.html.

8. Smith MJ, Thirthalli J, Abdallah AB, Murray RM, Cottler LB. Prevalence of psychotic symptoms in substance users: a comparison across substances. Compr Psychiatry 2009;50:245-250.

9. Blaszczhnski A, Walker M, Sharpe L, Nower L. Withdrawal and tolerance phenomenon in problem gambling. Int Gambl Stud 2008;8:179-192.

10. Griffith-Lendering MF, Wigman JT, Prince van Leeuwen A, Huijbregts SC, Huizink AC, Ormel J, et al. Cannabis use and vulnerability for psychosis in early adolescence--a TRAILS study. Addiction 2013;108:733-740.

11. Lin F, Zhou Y, Du Y, Qin L, Zhao Z, Xu J, et al. Abnormal white matter integrity in adolescents with Internet addiction disorder: a tract-based spatial statistics study. PLoS One 2012;7:e30253. 